\title{
MANFAAT METODE INQUIRY TERHADAP PENGAMATAN HASIL PRAKTIKUM LAS LISTRIK DI LABORATORIUM MANUFAKTUR POLITEKNIK META INDUSTRI CIKARANG
}

\author{
Agus Widodo ${ }^{1}$, Merdieco Rivandi ${ }^{2}$ \\ ${ }^{1}$ Program Studi Teknik Industri / Politeknik META Industri Cikarang / \\ agus@politeknikmeta.ac.id \\ ${ }^{2}$ Program Studi Teknik Industri / Politeknik META Industri Cikarang / \\ merdieco@politeknikmeta.ac.id
}

\begin{abstract}
The benefits of this observation are to determine the practical ability of industrial engineering students in the manufacturing process course before presenting treatment, to know the progress of student practicum in the manufacturing process after making changes to learning strategies, to understand the benefits of the learning process using the inquiry method by understanding the changes that occur in students. to the lecture practicum process and to find out what changes occurred in the practicum, after making changes to the use of learning methods and learning demonstrations. The strategy observation carried out by the researcher is quasi-observation. The type of observation used was able to analyze the problems that had occurred so far. The essence of this research observation is the learning activities of third semester students (Industrial Engineering) at the Cikarang Industrial META Polytechnic. The data collection strategy is carried out through practicum, observation of the practicum process and the results of the practicum with the welding results. whose data results show that there are still many students who do not understand it. The results of practicum achievement, after being given treatment, conducted training in both the control group and the experimental group. After this practicum method was held, there was a change in the values of the students. Not only beneficial for students, but there are very many records of changes in learning achievement after applying the comparison of previous and previous test results, in student practicums, the results show a significant difference.
\end{abstract}

Keywords: practicum, inquiry, electric welding, learning achievement

\begin{abstract}
ABSTRAK
Manfaat dari pengamatan praktikum ini, agar bertujuan untuk mengetahui kemampuan hasil praktikum mahasiswa teknik industri pada mata kuliah proses manufaktur sebelum pemberian perlakuan, mengetahui perkembangan praktikum mahasiswa pada mata kuliah proses manufaktur setelah mengadakan perubahan strategi pembelajaran, memahami manfaat proses pembelajaran menggunakan metode inquiry dengan dengn memahami perubahan yang terjadi denagn mahasiswa terhadap praktikum kuliah proses manufaktur dan untuk mengetahui perubahan apa yang terjadi dalam praktikum, setelah mengadakan perubahan pada penggunaan metode pembelajran inquiry dan pembelajaran demonstrasi. Adapun strategi pengamatan yang dilakukan oleh peneliti adalah pengamaatn Kuasi. Jenis pengamatan yang dipakai ini ternyata mampu manganalisa masalah yang selamam ini terjadi . Inti dari pengamatan penelitian ini adalah kegitan pembelajaran mahasiswa semester III (Teknik Industri) di Politeknik META Industri Cikarang. Strategi pengumpulan data pada penelitian dilakukan melalui praktikum, pengamatan terhadap proses praktikum pengelasan dan hasil praktikum las dengan hasil pengelasannya.Dari pengamatan dan penelitian ini memperlihatkan berdasar hasil praktikum, masih banyak mahasiswa yang belum memahami atau mengetahui strategi dalam praktikum las busur listrik pada kelompok kontrol dan kelompok eksperimen memiliki kemampuan awal yang hasil datanya menunjukkan masih banyak mahasiswa yang belum memahaminya. Hasil prestasi praktikum, setelah diberikan perlakuan, memperlihatkan adanya lonjakan baik pada grup kontrol maupun grup eksperimen. Setelah metode praktikum ini di terapkan, terdapat perubahan dengan nilai pada mahasiswa. Tidak hanya bermanfaat terhadap mahasiswa, tetapi sangat banyak catatan perubahan prestasi belajar setelah penerapan dengan
\end{abstract}


membandingkan hasil tes sebelumnya dan sesudahnya, pada praktikum mahasiswa menunjukkan hasil perbedaan yang cukup signifikan.

Kata kunci: praktikum, inquiry, las listrik, prestasi belajar

\section{PENDAHULUAN}

Politeknik META Industri Cikarang berada di tengah - tengah kawasan Industri . Politeknik ini mempunyai harapan untuk mendidik mahasiswa agar mempunyai ketrampilan dan pengetahuan yang sesuai dengan program studi yang menjadi pilihannya. Agar dikemudian hari setelah lulus, diharapkan mahasiswa siap untuk menghadapi persainagn di dunia industri maupaun berani untuk berwirausaha. Akan tetapi kondisi dilapangan membuktikan banyak sekali kendal - kendala yang di hadapi para lulusan dalam menghadapai dunia kerja .

Masalah yang sedang dihadapi mahasiswa di Politeknik META Industri Cikarang adalah rendahnya penerimaan materi oleh mahasiswa. Berdasarkan evaluasi terhadap Praktikum Las Listrik diketahui bahwa hasil belajar mahasiswa untuk praktikum Las Listrik angkatan 2018 masih terbilang rendah. Jumlah mahasiswa keseluruhan ada 12 mahasiswa, yang nilainya sampai 70 adalah sekitar 10\%, akibatnya harus ada sebuah perbaikan, baik melalui penugasan secara mandiri atau praktek agar memenuhi nilai yang telah ditentukan oleh program studi .

Banyak alasan, sehingga mahasiswa kelihatan rendah dalam memahami materi pada praktikum Las Listrik, yaitu: laboratorium tersebut kurang adanya alat dan bahan praktikum, belum adanya jobsheet sebagai pedoman praktek dan kurangnya cekatannya mahasiswa dalam mengikuti proses pembelajaran praktikum las listrik. Termasuk juga rendahnya kehadiran beberapa mahasiswa dalam praktikum. Sebab paling dominan justru karena kapasitas sumber listrik yang tidak sesuai dengan kapasitas mesin las busur listrik itu sendiri yang mempunyai sifat drop voltage, mesin las listrik di lab tidak dapat stabil yang mengakibatkan mahasiswa kesulitan mensetting las listrik dan arus dengan gerakan dalam waktu prose pengelasan. Termasuk juga kondisi arus listrik yang tidak stabil. Kestabilan gerakan electroda waktu mahasiswa praktikum sangat berpengaruh terhadap hasil bend akerja yang di las.

\section{METODE PENELITIAN}

Permasalahan yang sering terjadi dapat klasifikasikan kurang lebih seperti ini : Kurangnya sarana dan prasarana praktikum, Belum lengkapnya jobsheet untuk pedoman praktek, mahasiswa dalam mengikuti proses pembelajaran praktikum sebagian ada yang belum berani mencoba. Praktikum pengelasan merupakan bentuk ketrampilan, dimana keberanian mencoba menggunakan las listrik yang nantinya dapat menjadi bekal mahasiswa untuk menghadapi persaingan kerja yang semakin luar biasa hebat. Yang menjadi kendala mendasar pada pengamatan ini adalah saat praktikum las busur listrik yang sering turun jika mesin las tersebut hidup dua - duanya. Hal lain yang sering mempengaruhi adalah, besar kecilnya voltage dari mesin las yang sebagian mahasiswa belum mengerti.Termasuk juga kecepatan dalam menjalankan elctroda. Dimensi electroda dan strategi dalam meggerakkan electroda ketika mengelas dipengaruhi oleh kemampuan dan keberanian setiap mahasiswa yang berbeda, sehingga menyebabkan sulit untuk diubah. Setiap mahasiswa mempunyai modal dan keberanian yang berbeda - beda dalam praktik las busur listrik. Hal tersebut yang menyebabkan kualitas pembelajaran menjadi tidak berjalan semestinya, dikarenakana harus memperhatikan mahasiswa yang kurang cepat beradaptasi atau kurang berani mencoba untuk praktik.

\section{HASIL DAN PEMBAHASAN}

Kemampuan praktikum mahasiswa kita lambangkan dalam bentuk huruf dan angka, bisa juga dalam bentuk kata- kata yang menampilkan apa saja yang telah diperoleh oleh setiap mahasiswa pada pertemuan tertentu. Kemampuan mahasiswa dalam praktikum di laboratorium las listrik dinilai dari hasil praktikum pengelasan yang metodemenggunakan parameter penilaian. Parameter penilaian yang diterapkan dalam menentukan nilai mahasiswa adalah RPS. 
Tabel 1. Teknik Memperagakan dan Teknik Inquiry

\begin{tabular}{|c|c|c|}
\hline Macam Perbedaan & Teknik Memperagakan & Teknik Inquiry \\
\hline $\begin{array}{l}\text { Keahlian yang akan } \\
\text { didapat sesuai jenis } \\
\text { penilaian }\end{array}$ & $\begin{array}{l}\text { Memahami jenis keterampilan } \\
\text { berdasarkan standar yang sudah } \\
\text { di tentukan }\end{array}$ & $\begin{array}{l}\text { Menerapkan atau } \\
\text { Menganalisa sebuah } \\
\text { sistem }\end{array}$ \\
\hline Strategi mengajar & $\begin{array}{l}\text { Dosen mempraktikkan kegiatan } \\
\text { kepada kepada mahasiswa }\end{array}$ & $\begin{array}{lr}\text { Mahasiswa } & \text { melaksanakan } \\
\text { kegiatan } & \text { sendiri, } \\
\text { dosen } & \text { sebatas } \\
\text { mendampingi } & \text { mahasiswa }\end{array}$ \\
\hline Jenis metode & $\begin{array}{l}\text { Jenis berdasarkan } \\
\text { pemanfaatannya }\end{array}$ & $\begin{array}{l}\text { Jenis berdasarkan bentuk } \\
\text { pendekatan ke mahasiswa }\end{array}$ \\
\hline Fungsi dosen & $\begin{array}{l}\text { Sebagai instruktur, teknik } \\
\text { memperagakan tidak bisa } \\
\text { lepas dari penjelasan secara } \\
\text { lisan }\end{array}$ & 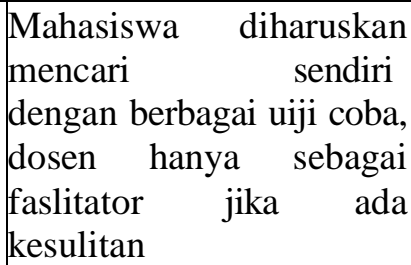 \\
\hline
\end{tabular}

Pengertian pengelasan dengan menggunakan las listrik adalah sebagai berikut : proses penyatuan dua buah logam dengan cara memanaskan .

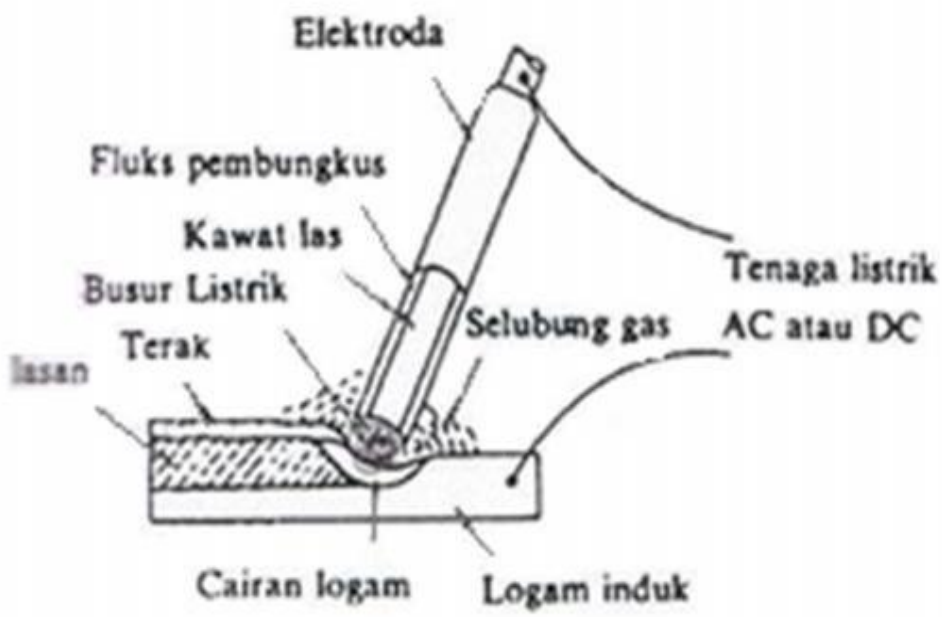

\section{Gambar 1. Las Busur Listrik}

Keuntungan las Busur Listrik :

1) bisa dilakukan dimana saja .

2) bisa untuk menyambung berbagai jenis macam material logam .

3) mudah pemakaiannya .

4) dapat mengelas berbagai sudut yang sulit dan dalam .

5) pilihan elektrodanya sangat banyak di pasaran.

6) resiko kecelakaan kerjanya sedikit .

7) alat K3 nya tidak terlalu banyak dan mudah di dapat 
Kekurangan las Busur Listrik :

1) electrodanya panjangnya terbatas.

2) banyaknya fluks dari hasil pengelasan.

3) hanya untuk logam ferro

4) ukuran elektroda harus menyesuaikan ketebalan material yang di las .

Jenis ketrampilan las yang akan dipraktekkan adalah mengelas teknik fillet. Ketrampilan ini dipilih karena bisa mewakili berbagia jenis ketrampilan mengelas dalam las busur listrik .

Teknik mengelas fillet :

1) pengelasan fillet :

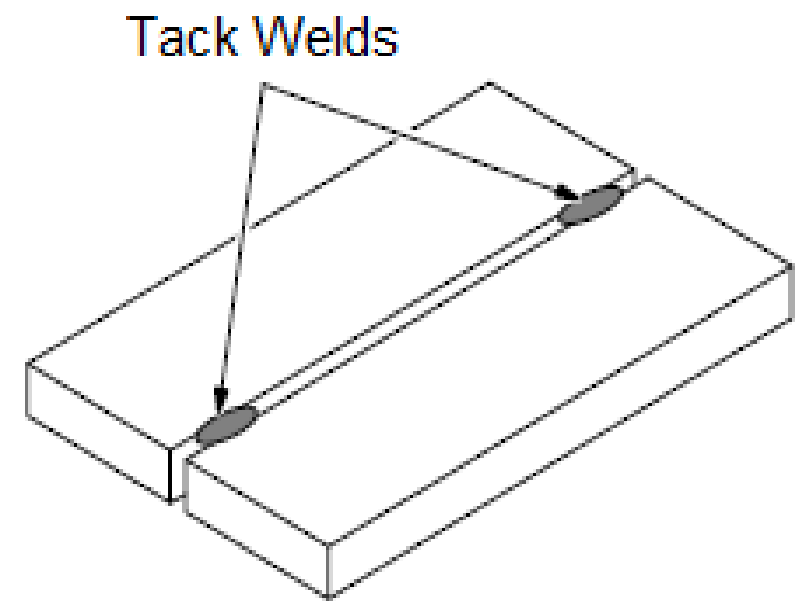

Gambar 2. Proses Las Titik

2) dalam proses penyambungan ini cukup mudah, dikarenakan sudah memakai las titik sebelumnya.

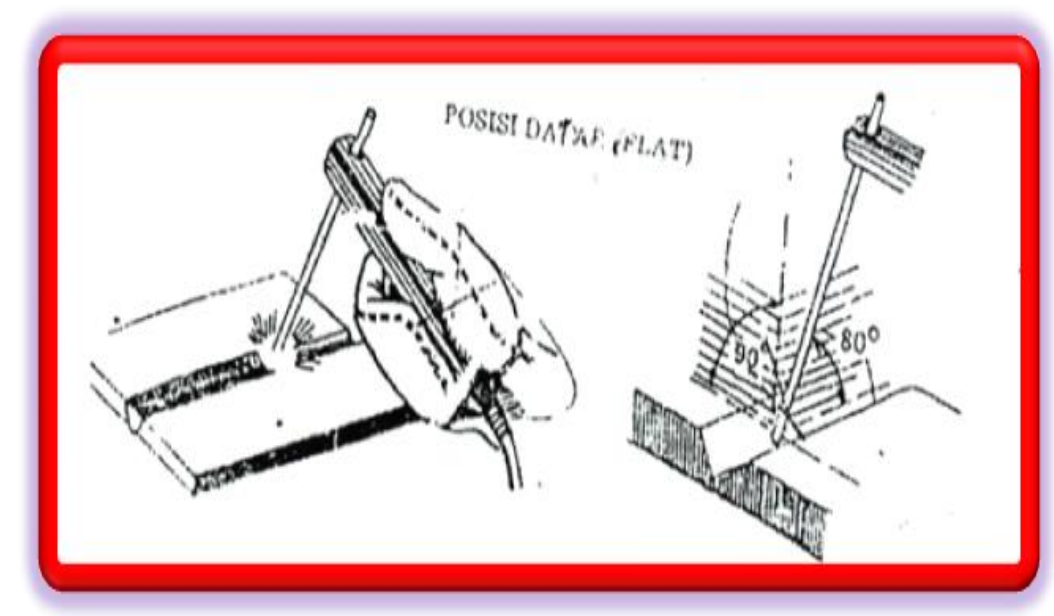

Gambar 3. Gerakan elektroda

4) dalam proses pengelasan ini pemakaian electroda disesuaikan dengan ketebalan benda kerja atau material yang akan dilas. 


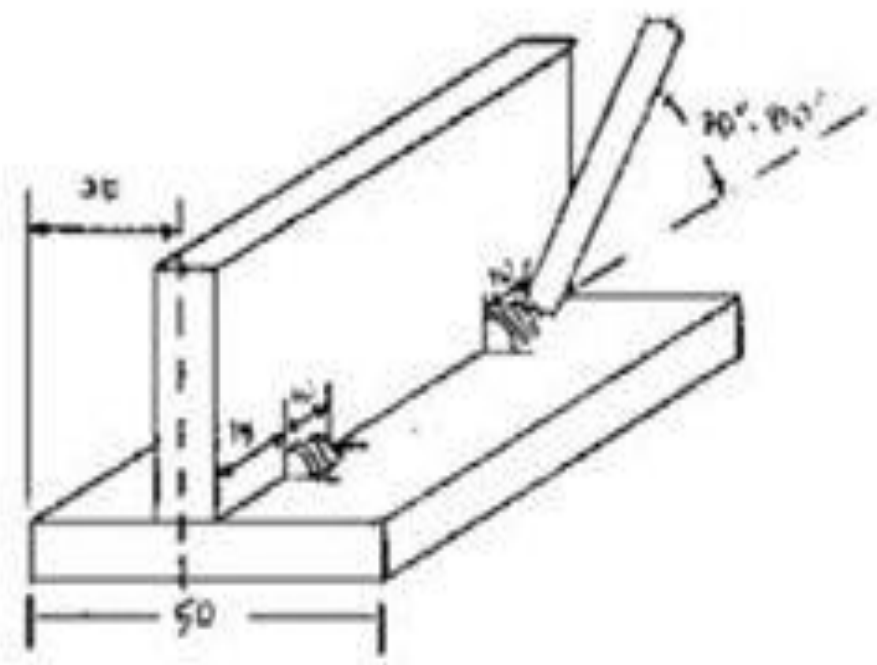

Gambar 4. Ukuran ketebalan

Hal - hal yang menjadi tanda baik tidaknya sambungan Las tersebut :

a. Dimensi

Hal - hal yang menjadi syarat hasil las yang akan baik adalah besar tingginya tegangan, kestabilan gerakan, tinggi rendahnya antara electroda dan benda kerja.

1) tegangan. Mesin las buusr listrik pada umumnya mempunyai tegangan 50-90 Volt .

2) arus. Dimensi elektroda, dimensi benda kerja yang dilas, type elektroda yang digunakan, karakteristik material dan sebagainya menjadi pertimbangan dalam proses pengelasan.

Tabel 3. Pengaruh Diameter dan Tebal Benda Kerja

\begin{tabular}{|c|c|c|}
\hline $\begin{array}{c}\text { Ukuran } \\
\text { Material }\end{array}$ & Ukuran elektroda & Arus \\
\hline sampai 1 & 1 & $30-40$ \\
\hline $1-1.5$ & 1.5 & $40-70$ \\
\hline $1.5-2$ & 2 & $70-90$ \\
\hline $2-43$ & 2.5 & $85-140$ \\
\hline $4-6$ & 3 & $110-160$ \\
\hline $7-12$ & 4 & $150-210$ \\
\hline
\end{tabular}

Arus dalam proses pengelasan dan parameter las yang langsung bisa mempengaruhi pengelasan dan kecepatan proses pencairan logam. Akibat tinggi arus las makin besar pula proses pengelasan dan kecepatan pencairannya dalam pengelasan. Besarnya tegangan pada teknik pengelasan mempengaruhi baik tidakanya produk yang di las. Bila tegangan terlalu rendah, akan mengakibatkan: a) las listrik menjadi tidak stabil tegangannya, b) panas yang di hasilkan mesin las kurang tinggi c) proses pegelasan kurang dalam dan , d) hasil proses pengelasan lebar tidak rata dan terak terlihat begitu banyak . 


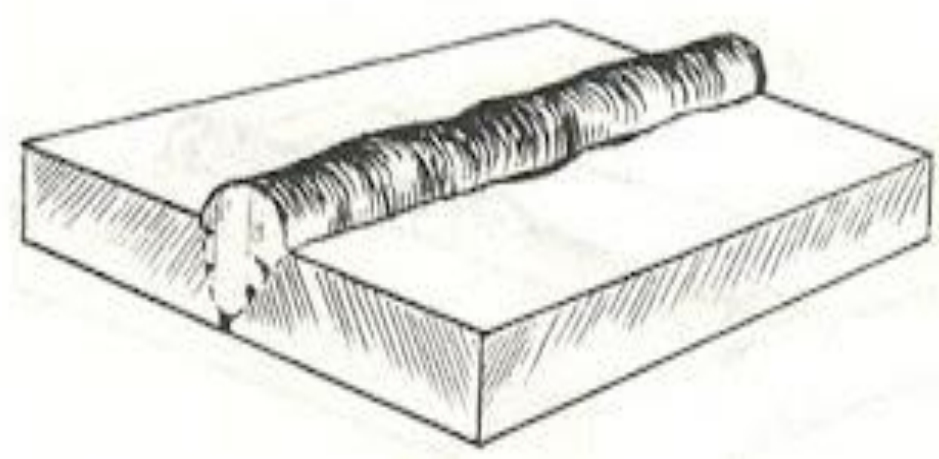

Gambar 5. Proses pengelasan sangat rendah posisinya

Jika ampere pada pengelasan sangat tinggi, tentunya elektroda akan sanagt cepat mencair dan berdampak : a) hasil pengelasan menjadi lebar dan datar b) hasil pengelasan yang terlalu dalam c) banyak nya percikan di sekitar rea pengelasan

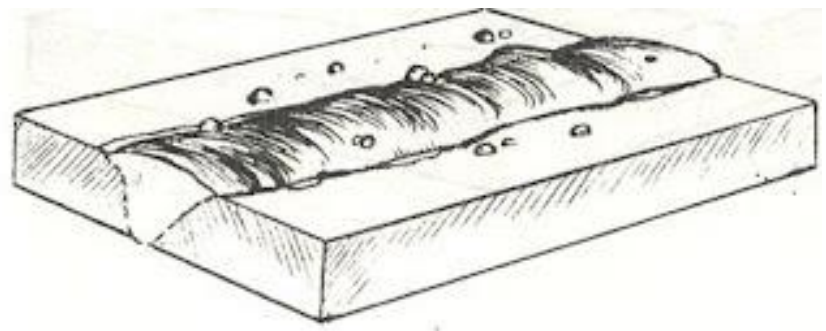

Gambar 6. Proses pengelasn sangat tinggi posisinya

1) Tinggi dan panjangnya proses pengelasan sangat mempengaruhi keberhasilan atau kualitas hasil dari pengelasan, untuk itu perlu dipersipakan strategi dan teknik atau gerakan stabil dalam menarik busur las ini:

a) Hal ini akan menyebabkan suatu hasil pengelasan berupa kedalaman yang dangkal, dan area terdekat pengelasan banyak percikannya, serta hasil pengelasan sangat lebar dan banyak percikan .

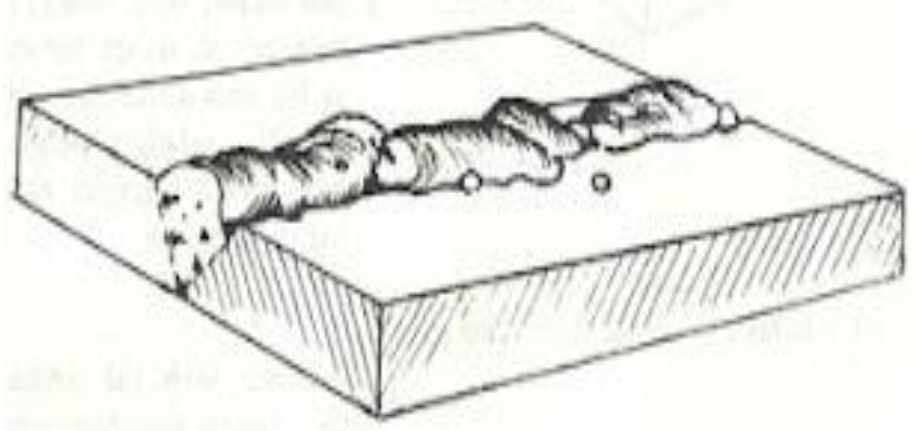

Gambar 7. Proses pengelasan yang sangat tinggi 
a) Biasanya hasil pengelasan menjadi kecil dan tidak halus, bisa juga karena elektroda menyatu pada benda kerja yang di las dan juga adnay banyak lobang di sekitar hasil pengelasan. Adanya lobang - lobang pada benda kerja ini menunjukkan bahwa logam las telah membeku dengan segera pada saat proses pengelasan mau selesai.

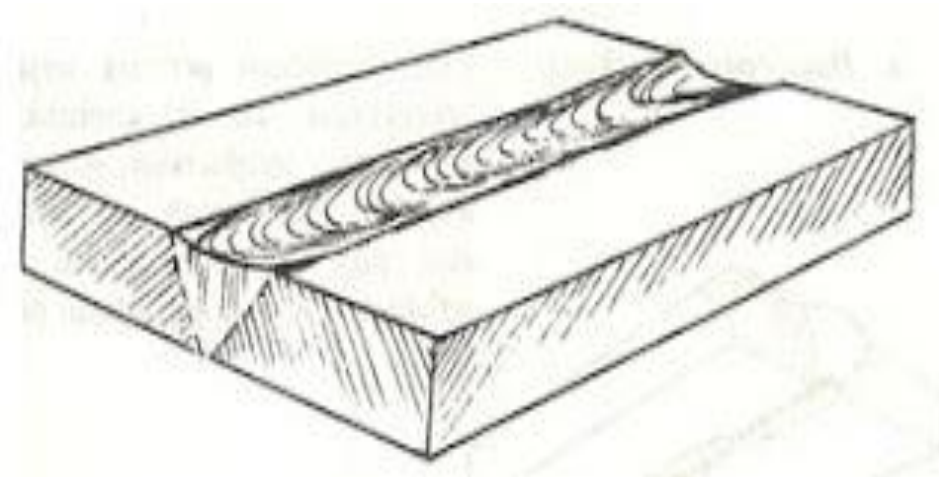

Gambar 8. Pengelasan terlalu rendah

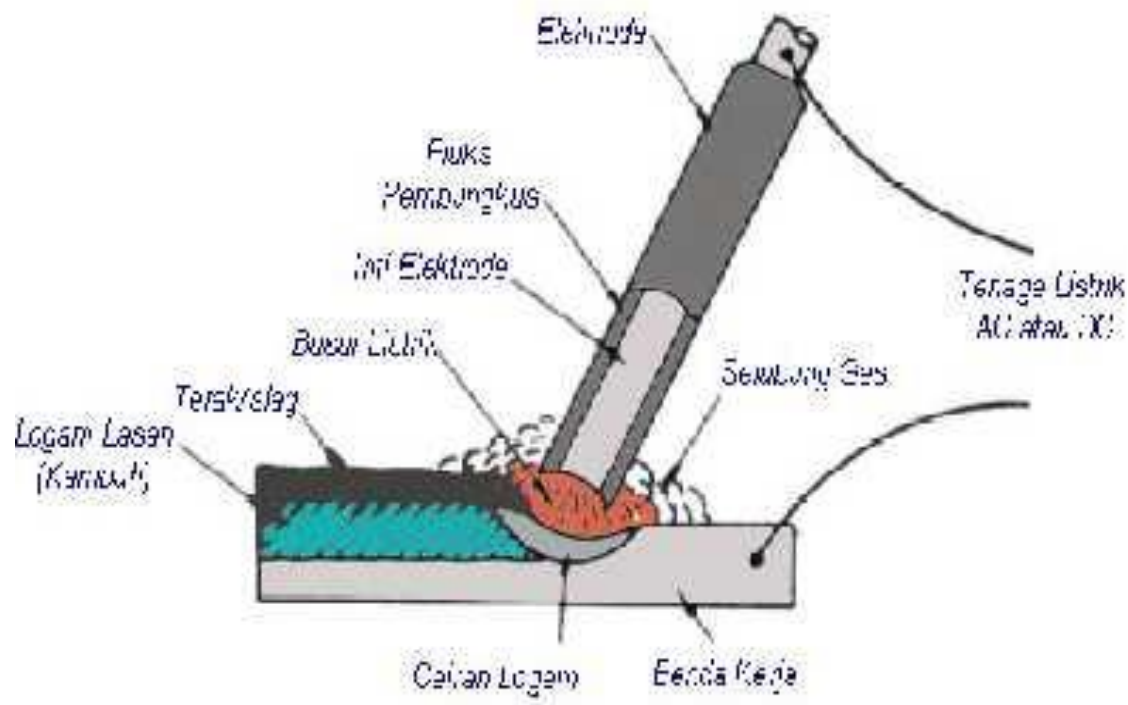

Gambar 9. Hasil pengelasan yang baik

\section{KESIMPULAN DAN SARAN}

1. Perlunya perawatan rutin setelah pemakaian atau pengoperasian mesin las dari mingguan, bulanan ,triwulan, semester dan tahunan.

2. Perlunya petunjuk pemakaian yang benar dan perawatan sederhana dari operator mesin las tersebut.

3. Pentingnya memahami ukuarn voltage mesin dengan ukuran ketebalan material yang di las.

4. Perlunya kestabilan gerakan electroda sewaktu praktikum pengelasan . 
Jurnal Inkofar * Volume 5 No. 2, Desember 2021 * ISSN: 2615-3645 (Print) / ISSN: 2581-2920 (Online)

Tersedia secara online di: http://www.politeknikmeta.ac.id/meta/ojs/

\section{DAFTAR PUSTAKA}

Widharto S., 2006, Petunjuk Kerja Las, Cetakan Keenam, PT Pradnya Paramita, Jakarta.

Wiryomumarto, harsono dan okumura, toshie. 2008. Teknologi Pengelasan Logam. Cet.10. Jakarta: Pradnya Paramita, 2008.

Pelajar. Anas Sudijono. (2006). Pengantar Statistik Pendidikan. Jakarta: PT Raja Grafindo Persada. Andi Prastowo. (2011). Memahami Metode-metode Penelitian. Yogyakarta: Ar- ruzz Media.

ASM Volume 6, 1993. "Welding, brazing, and soldering," The ASM Handbook Committee

Heri Rahyubi. (2012). Teori-teori Belajar dan Aplikasi Pembelajaran Motorik.Bandung: Nusa Media.

Surdia, Tata dan Shinroku Saito. 1999. Pengetahuan Bahan Teknik. Jakarta: Pradnya Pramita.

Nana Sudjana. (2005). Penilaian Hasil Proses Belajar Mengajar. Bandung: PT. Remaja Rosdakarya Offset.

Schey John A, 2011, Proses Manufactur. Andi, yogyakarta.

Okumura, T. \& Wiryosumarto, H. 1996, Teknologi Pengelasan Logam, Pradnya Paramita, Jakarta.

Pupuh Fathurrohman. (2007). Strategi Belajar Mengajar. Bandung: Aditama. 